\title{
Traduzir a poesia brasileira ${ }^{1}$
}

É constrangedor confessar, mas antes de eu ir ao Brasil em 2003, ignorava por completo a riqueza da poesia modernista desse grande país. Que as pessoas em geral a desconheçam era para mim considerado normal, mas o caso é que eu, no vigor da juventude, por escrever e pesquisar sobre poesia moderna, costumava gabar-me do meu conhecimento em relação à poesia moderna no mundo. Sou uma pessoa que costumo manter atualizado meu mapa-múndi mental da poesia moderna. Mas apenas depois de chegar ao Brasil é que me dei conta de que, por mais que eu conhecesse inúmeros poetas de peso "produzidos" pelos países vizinhos e pudesse aplicar meus parcos conhecimentos de espanhol para ler as obras originais de Borges, Neruda, Vallejo e Octavio Paz, entre outros, não havia em minha memória nome algum de poetas brasileiros; que dirá de alguma obra.

$\mathrm{Na}$ realidade, eu não era o único. $\mathrm{O}$ desconhecimento total da poesia brasileira entre os poetas contemporâneos chineses ainda é uma situação comum. Neste ponto há um evidente contraste do apetite cosmopolita dos poetas contemporâneos chineses em relação à leitura de obras de seus pares estrangeiros. Desde o fim da Revolução Cultural (1976), apesar de a poesia chinesa estar em baixa, de forma geral, a atitude dos poetas perante a literatura de outros países ainda se localiza no período do canibalismo brasileiro: os sucessivos ápices de tradução poética serviram de forma velada como uma surpreendente força criadora da poesia contemporânea da China. Na atualidade, ainda que um poeta chinês não esteja numa sala de aula da universidade como eu, e não possua grandes conhecimentos de língua estrangeira, ele ou ela também é conhecedor da poesia moderna mundial.

1 Tradução de Márcia Schmaltz, com revisão de Telma Franco Diniz. (Nota do Ed.) 
Acredito, porém, que para quase todos os poetas chineses a poesia brasileira é uma rara página em branco.

Às vezes inclusive desconfio se aquela linha criada há mais de quinhentos anos pelo Tratado de Tordesilhas também não teria sido riscada no âmbito da tradução de poesia na China. Esta demarcação de território para o lado da América espanhola fez com que os leitores chineses tivessem acesso a uma variedade de traduções, inclusive de grandes poetas ainda presentes nos dias de hoje como Juan Gelman e José Emilo Pacheco, que estiveram na China para participar de saraus poéticos. Já do lado da América portuguesa, de que faz parte o Brasil, as publicações são esporádicas, à margem do círculo literário chinês, e ocorrem ora pela produção independente da Embaixada do Brasil na China (Antologia da poesia brasileira (1994) e Antologia poética de Mário Quintana (2007) realizada pelo tradutor de espanhol Zhao Deming); ora pelas esparsas publicações em revistas literárias acadêmicas.

No início de 2004, quando eu já era professor visitante na Universidade de Brasilia há vários meses, apoiei-me na similaridade linguística entre o espanhol e português, somada a minha aprendizagem individual, e conseguia ler alguma coisa em português. Entretanto, devido à falta de autoconfiança, meu contato inicial com a poesia brasileira foi mediada pela edição bilíngue português e inglês $A n$ Anthology of Twentieth Century Brazilian Poetry de Elizabeth Bishop (1997). Li esta obra com o auxílio de um dicionário e quando a leitura de um verso ultrapassava a minha capacidade de compreensão, socorria-me com a tradução correspondente em inglês. Este livro teve uma forte influência sobre mim, pois foi através dele que conheci Manuel Bandeira, Carlos Drummond de Andrade, Cecília Meireles, Vinícius de Moraes, Murilo Mendes e João Cabral de Melo Neto, entre outros. O mais importante foi que este livro inspirou-me a traduzir a poesia brasileira.

Comecei por traduzir os poemas de Vinícius de Moraes. Escolhi este poeta considerando duas questões: a primeira foi o tom lírico de sua poesia. A não ser por algumas analogias exageradas e francas contidas em alguns versos, sua poesia não é muito difícil e não subjaz trilhas sinuosas e "passagens subterrâneas" complexas. Exige apenas que o tradutor aproprie-se da medida exata de seu lirismo boêmio repleto de uma masculinidade expansiva e laissez-faire. A segunda questão refere-se à tradição da poesia contemporânea chinesa. Na década de 1980 estava em voga o a poesia da confraria dos durões, o “rudismo" ““莽汉主义” mănghàn z̧hüyì boorism) em Sichuan, minha terra natal. Associei a poética do movimento com a temática lírica desinibida e explosiva de Vinícius. Nos anos 1990, o "rudismo" foi isolado pela tendência sóbria, narrativa e irônica da poesia chinesa. Inclusive eu desprezava igualmente o movimento literário, mas no período em que li Vinícius, a minha poesia também se tornou um tanto "sem papas na língua" e passei a achar 
que o lirismo exacerbado não provocaria necessariamente o colapso interno da estrutura poética.

O verso "Que a mulher se socialize elegantemente em azul, como na República Popular Chinesa" do poema "Receita de mulher" de Vinícius de Moraes (2004, 53) foi o que me provocou à tradução. Aos olhos de um poeta chinês, este verso parece um tanto abrupto e portador de uma interessante imaginação transcultural; pois, para os chineses contemporâneos, não há nenhuma relação entre as mulheres vestirem-se com trajes azuis de operário ou farda verde-oliva e a concepção de beleza. Sem dúvida alguma, "Receita de Mulher" é um poema magnífico, que engendra uma imaginação excêntrica, apesar do machismo, incorreto politicamente, que se centra no corpo feminino. Entretanto aprecio muito. Propositadamente evitei a minha escrita poética e o traduzi intencionalmente no tom do "rudismo" (boorism) dos anos 1980. Ao retornar à China em 2005, muitas vezes declamei a versão chinesa deste poema em saraus e obtive boa reação do público presente. Os jovens leitores chineses apreciaram especialmente a minha tradução do último verso do "Soneto de Fidelidade": "Que não seja imortal, posto que é chama/ Mas que seja infinito enquanto dure". Dizem que a compreensão sobre a "fidelidade" manifesta no poema difere muito da visão tradicional do Oriente, e serve de justificativa sublime para o rompimento amoroso de universitários.

Antes de eu deixar o Brasil em 2005, além de Vinícius de Moraes, eu também havia traduzido alguns poemas de Manuel Bandeira, Carlos Drummond de Andrade, Mário Quintana, Paulo Leminski, Ana Cristina César. Contudo, logo descobri minha meta de tradução: João Cabral de Melo Neto (JCMN daqui por diante), mestre da poesia modernista brasileira.

O "encontro" com JCMN foi para mim uma alegria imensa. Meu gosto pela leitura de poesia é amplo e variado, aprecio desde a "simplicidade" da poesia de Garcia Lorca e Jacques Prévert, passando pela "improvisação" de Frank O’hara e Nicanor Parra. Entretanto, os poemas que mais me provocam êxtase na leitura ainda são aqueles que demonstram complexidade na composição da estrutura interna através do jogo com as palavras; a habilidade em manipular com frieza e primazia os versos de forma a surgir uma simetria entre o mundo real e o mundo interior do poeta. Para mim, esses poetas possuem alegria na forma, com tênues reviravoltas semânticas que fazem com que nos debrucemos sobre a perspicácia realista da poesia moderna, cuja criatividade integra uma linguagem expressiva e imaginação ilimitada. A meu ver, JCMN faz parte dessa classe de poetas.

O primeiro poema que li em português de forma autônoma sem precisar recorrer ao dicionário ou a tradução inglesa foi "O Engenheiro" de JCMN (1978, p. 195). Fui atraído pela sobriedade, transparência, objetividade de sua meta poesia 
obstinada, embebida na experiência vivaz e real (especialmente em sua memória singular do Nordeste brasileiro). Sua poesia é leve como uma esponja e inteiramente arejada. Ao ler seus poemas, surpreendemo-nos com a capacidade de absorção de água desses "poros" retóricos. Alguns alunos da Universidade de Brasília, ao saberem de meu interesse pelo poeta pernambucano, emprestaram-me várias de suas antologias. Lembro-me de chegar as minhas mãos um daqueles livros que de tão gasto pelo manuseio, era forçosamente denominado de livro pelo remendo com fita colante. Este aluno que me emprestou o dito livro justificou-se dizendo que o livro estava naquele estado de tanto seu avô, seu pai e ele próprio o folhearem. Dentro da minha mala de retorno do Brasil ainda trouxe um CD recitado pelo JCMN. Ouvir o ritmo, o tom, a transição e a finalização na voz do próprio poeta, ajudaram-me de forma surpreendente na tradução.

Por volta de 2008, concentrei-me na tradução de mais de trinta poemas de JCMN. Resolvi traduzi-los para minha autossatisfação e por acreditar que muitos de seus elementos poéticos poderiam servir de referência à escrita do círculo literário chinês daquele período. A poesia contemporânea chinesa a partir de 1990 iniciou um movimento de crítica à poesia desenvolvida na década de 1980, que foi avaliada como de uma coloração subjetiva e de uma lírica exacerbada. Os poetas que detinham o "direito à palavra" defendiam uma nova visão, em que a poesia deveria introduzir elementos narrativos concretos e sensibilizadores para corrigir a relação entre a sonoridade do poema com a realidade. Embora esta tendência ajudasse a engendrar uma impressão moderna complexa, que incrustava em vários níveis a ficção com uma realidade aparente, decorridos mais de dez anos, muitos poetas da nova geração, ao seguirem a poesia da década de 1990, por vezes foram infelizes em suas tentativas, pois transformaram a narrativa que era para ser um meio em uma narrativa objetiva. Com isso, a força criadora da poesia modernista chinesa ficou engessada. Eu acredito que a obra de JCMN contribui com uma saída mais inteligente e "antilírica": ao descartar a emotividade no nível superficial como premissa, possui uma atitude sóbria e cautelosa ao sondar a metalinguagem e experienciar novas formas. Permite à escrita se tornar uma máquina poética que manipula uma força complexa, que ao final faz com que a poesia volte a construir "o mundo justo,/mundo que nenhum véu encobre".

Confesso que, comparada a Vinícius de Moraes, a tradução da poesia de JCMN é muito mais difícil. Em relação à postura da tradução poética, acredito que o poeta como tradutor sempre possui vantagens em relação ao tradutor profissional; quando Robert Frost aponta que "a poesia é o que se perde na tradução",

2 [Poetry is what gets lost in translation] 
penso que isto pode ser remediado quando a tradução é realizada por um poeta (poet as a translator) que, no papel de tradutor, pode empregar a técnica de floreio poético para compatibilizar a forma da língua de partida na língua de chegada. Porém, ao traduzir JCMN, percebi que nas camadas profundas de seus poemas esconde-se uma engrenagem estrutural conectada densamente e que só funciona na língua portuguesa.

Encontrei uma engrenagem fortificada e escondida na língua do poeta, cheia de subterfúgios linguísticos e com alto grau de dificuldade para se "transpor" para a forma da poesia contemporânea chinesa. Às vezes abandonei a maneira de reconstruir aquela forma em armadilhas, e mudei a estratégia para a tradução literal e, através da adequação do tom e da mudança do estilo, enfatizei o efeito expressivo, insinuando o efeito em espiral. Por exemplo, "Tecendo a Manhã". Este poema parece simples, inclusive remete a fantasia naif de Joan Miró, mas contém vários jogos de palavras, que não é possível de se recriar em chinês, especialmente na segunda estrofe:

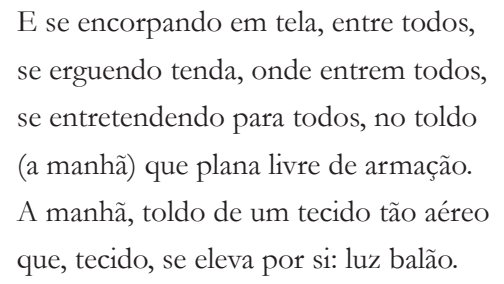

Da mudança a partir de "se encorpando" a "se erguendo" até "se entretendendo" e da gradação de "tela" a "tenda" até "toldo", e a diferença de classe gramatical de "tecido" nos últimos dois versos, foram todos muito difíceis de serem reproduzidos em chinês. Especialmente "entretendendo", palavra esta inventada pelo próprio JCMN, que incrusta os sintagmas "entre", "entender", "tender" e "tenda", e cujo sentido flutua sem direção, tornando impossível encontrar equivalência para expressá-las em chinês. Eu havia conjecturado em traduzir o poema ao estilo de Zhang $\mathrm{Zao}^{3}$, queria produzir um efeito similar deste poeta contemporâneo, em que as palavras amalgamadas incitam-se entre si. Mas não fui capaz e, por fim, utilizei o tratamento convencional da entonação da poesia chinesa dos anos 2000, traduzindo o sentido superficial do poema.

3 Disponível em: http://www.poetryinternationalweb.net/pi/site/poet/item/979 (N.T.) 
Em 2008, a revista "Poesia Contemporânea Internacional" encomendou-me um especial com a tradução de alguns poemas e apresentação de JCMN. Mais tarde recebi retornos positivos, como do importante poeta chinês contemporâneo Duo Duo que, como JCMN, também foi galardoado com o Prêmio Internacional Neustadt de Literatura. Ele telefonou-me emocionado dizendo que há muitos anos não lia poemas estrangeiros de "peso" como estes. Tang Xiaodu (2008), importante crítico literário contemporâneo, também manifestou em um artigo a importância do termo "vazio" no poema de JCMN e uma fonte de inspiração para a poesia chinesa contemporânea. Outro importante crítico literário, Jing Wendong, citou e discutiu o verso "não nos dão seus municípios / mas outras nacionalidades" (CABRAL DE MELO NETO, 1990, p. 56) do poema "A Literatura como Turismo". Mais tarde, a revista "Poetry", a mais respeitável no sistema oficial nacional também organizou um dossiê com poemas e apresentação de JCMN, traduzido e escrito por mim.

Em 2011, interessei-me intensamente por O Amor Natural, edição póstuma de Carlos Drummond de Andrade. Eu já havia traduzido alguns poemas deste poeta, pensava que a sua poesia seria tanto aceita pelo leitor comum, como reconhecida pelos poetas mais calejados. Contudo, devido à limitação de tempo, nunca havia traduzido seus poemas de maneira intensiva. Por um acaso, li a edição eletrônica de $O$ Amor Natural e fiquei impressionado com a criatividade na linguagem e o tratamento do tema relacionado ao ato sexual por um octogenário. Tradicionalmente, a poética chinesa carece de sensualidade, o que talvez seja relacionado à cultura da Ásia oriental, que trata o ato sexual como um assunto velado. Nos últimos anos, começaram a surgir movimentos e manifestações individuais que possuíam uma escrita sensual, entretanto utilizavam o tema do sexo e do corpo como subterfúgio para chamar a atenção para outras questões. Por exemplo, dez anos atrás houve um movimento poético de jovens chamado "Escrever com a parte inferior do corpo". Eles escreveram poemas eróticos, mas o foco não estava na concretização do ato em si, mas queriam através do tema protestar contra a ordem literária. Alguns poetas expoentes também conseguiram com êxito escrever sobre assuntos sensíveis como história e política real através do enquadre da poesia sensual. Entretanto, quase nenhum poeta contemporâneo chinês pode lidar de frente com o sexo, nem como energia para a paixão, nem como um recurso de criatividade da linguagem. Ao traduzir a metade dos poemas de $O$ Amor Natural publiquei numa página da rede social mais visitada pelos jovens e recebi excelentes críticas. Muitos leitores me escreveram dizendo que a leitura dos poemas de Carlos Drummond havia mudado seu conceito quanto ao tabu sobre "sexo", bem como revelado uma faceta desconhecida da poesia e de como este gênero literário também podia ser 
divertido! Entretanto, a divulgação de $O$ Amor Natural limitou-se apenas à internet. Tentei contatar uma editora especializada em literatura do segmento jovem para a publicação em chinês, mas apesar da editora ter apreciado os poemas, ela confessou que, de acordo com a política de publicação governamental chinesa, não seria possível publicá-lo oficialmente. Neste interim outra editora me contatou, por ter vislumbrado, em Carlos Drummond de Andrade, uma poesia excelente e não muito distante do gosto do leitor chinês. Assim, convidou-me para traduzir outra antologia de seus poemas que não fosse de $O$ Amor Natural.

Outra questão interessante é a reação dos leitores chineses aos concretistas como Haroldo de Campos e Augusto de Campos. Eu tenho exposto a poesia concreta na disciplina "Poesia Mundial a partir do Modernismo" e também publicado numa revista uma apresentação sobre o Concretismo e o Neoconcretismo. Entretanto, percebi o desinteresse dos poetas chineses (tanto dos poetas universitários quanto dos renomados) pelo Concretismo. Isto não é uma realidade isolada, apesar de a poesia contemporânea chinesa ter se renovado, raramente ocorre uma interceptação com a poesia concreta, visual e sonora entre outras áreas experimentais. Do meu ponto de vista, a causa desse desinteresse advém de dois motivos: um concerne à escrita chinesa ser iconográfica por natureza, já existindo um forte apelo visual, por isso, os poetas chineses não precisam interferir nos caracteres para obter tal efeito, como seus pares ocidentais. Segundo, desde a Antiguidade a China possui uma definição muito clara e rígida sobre a poesia. Mesmo na China contemporânea, a poesia já teve um período de renovação, mas sempre permanece uma delimitação tênue muito discreta, aceita coletivamente. Desta forma, a poesia concreta, visual e sonora, entre outras, ultrapassa a linha limítrofe da poesia e entra no âmbito das artes plásticas. Na China atual, existem algumas tentativas esparsas de cruzar os domínios da arte, mas na maioria das vezes, as áreas permanecem independentes, como água e óleo não se misturam. Por isso, apenas dois tipos de leitores se interessam pela minha apresentação sobre o concretismo, o neoconcretismo e a poesia visual: os aficionados em computação e os artistas plásticos.

Por último quero dizer que meu nível de domínio de português é muito limitado. Esta constatação limita a minha atuação para traduzir a poesia brasileira num maior volume. Apesar de eu não acreditar que Poetry is what gets lost in translation, não compartilho muito a ideia de transcriação em relação ao texto de partida. Eu ao final acredito no trabalho do "poeta como tradutor", mas o melhor é partir da língua do original, sem passar por língua intermediária (há o caso de Ezra Pound que não entendia de chinês, mas "traduziu" a poesia da dinastia Tang. A meu ver isto deve ser considerado como criação pessoal e não uma tradução). Caso um 
dia meu nível de português possa se elevar a altura, certamente, traduzirei mais poemas brasileiros. Contudo acredito que, mesmo que haja este dia, eu não seria crível como um tradutor profissional, porque a partir do meu relato acima você pode ter percebido que, na maior parte do tempo, a tradução está a serviço da elevação de minha criação poética. Geralmente, quando estou no auge de minha produção é o período fulcral de minha escritura poética, e quando não consigo escrever poesia, e não querendo afastar-me dela, uma boa alternativa é traduzir poesia. No ensaio "Poeta como tradutor, O poeta e tradutor estadunidense Kenneth Rexroth (1987, p. 171) afirmou:

\begin{abstract}
Translation, however, can provide us with poetic exercise on the highest level. It is the best way to keep your tools sharp until the great job, the great moment, comes along. More important, it is an exercise of sympathy on the highest level. The writer who can project himself into the exultation of another learns more than the craft of words. He learns the stuff of poetry. It is not just his prosody he keeps alert, it is his heart. The imagination must evoke, not just a vanished detail of experience, but the fullness of another human being.
\end{abstract}

\title{
Referências
}

Antologia da Poesia Brasileira 《巴西诗选》, tradução de Zhao Deming. Pequim: Embaixada do Brasil em Pequim, 1994.

BISHOP, Elizabeth. Anthology of Twentieth Century Brazilian Poetry. Middletown: Wesleyan University Press, 1997.

CABRAL DE MELO NETO, João. Antologia Poética. Rio de Janeiro: Livraria José Olympio Editora, 1978.

Museo di Tutto. Milano: Libri Scheiwiller, 1990.

DRUMMOND DE ANDRADE, Carlos. O Amor Natural. Rio de Janeiro: Record, 1992. HU, Xudong. “若昂・卡布拉尔诗选” (Seleção de poemas de João Cabral). In: Poesia Contemporânea Internacional, v. 2. Pequim: China Writers Publishing House, 2008.

“若昂・卡布拉爾：詩歌工程師” (João Cabral: um engenheiro da poesia). In: Poetry, Vol. 1, n. 608, 2011, pp. 53-55.

“若昂・卡布拉尔诗选” (Seleção de poemas de João Cabral). In: Poetry, Vol. 1, n. 608, 2008, pp. 50-53.

"Poesia brasileira em ideogramas", tradução de Hu Xudong. In: Poesia Sempre. Rio de Janeiro: Fundação Biblioteca Nacional, ano 15, n. 27, 2007, pp. 87-107.

QUINTANA, Mário. Antologia poética de Mário Quintana, tradução de Zhao Deming e Ge Xiaocheng. Porto Alegre: EDIPUCRS.

REXROTH, Kenneth. "The Poet as Translator", In: World outside the window: the selected essays of Kenneth Rexroth. Nova Iorque: New Directions Publishing, 1987. 
MORAES, Vinicius de. Soneto de Fidelidade e outros poemas. São Paulo: Ediouro, 2004.

TANG, Xiaodu. "Prefácio". In: Poesia Contemporânea Internacional, v. 2. Pequim: China Writers Publishing House, 2008.

翻译巴西诗歌

胡续冬

说起来非常汗颜，2003年我去巴西之前，对这个庞大的国家丰富的 现代诗歌资源竟然一无所知。一般人一无所知也就罢了, 偏偏我那个时 候年轻气盛, 因为既写诗又做一点现代诗歌研究的缘故, 我总是自训对 世界各地的现代诗歌多少都有些了解, 脑子里有一幅不断被刷新的世界 现代诗歌地图。但只是到了巴西以后, 我才恍然意识到, 尽管我对巴西 的各个说西班牙语的邻国 “出产” 了哪些重量级的诗人如数家珍、尽管 我甚至可以借助一点粗浅的西班牙语阅读博尔赫斯、聂鲁达、巴列霍、 帕斯等人的少许原作, 但我脑子里居然没有存下任何一个巴西诗人的名 字, 更别提他们的作品。

事实上, 不只我一个人如此, 中国当代诗人对巴西诗歌的全然陌生 是一个极其普遍的现象, 这一点与中国当代诗人们阅读外国同行作品时 洋溢出来的那种引人注目的世界主义胃口形成了鲜明的反差。中国的诗 歌界从1970年代末期 “文化大革命” 结束以来一直到现在, 尽管有过一 些低谷, 但总体上, 在对待其他国家文学资源的态度上, 还始终处在巴 西文学里所谓的“食人主义” 时期, 一波又一波诗歌译介的高潮隐秘地 塑造着中国当代诗歌惊人的创造力。一个普通的中国当代诗人, 即使他 (她) 没有像我一样在大学里执教, 也没有掌握足够的外语知识, 他 ( 她）头脑中的世界现代诗歌地图也同样精微繁复。但巴西诗歌对几乎所 有的中国诗人来说都是一个罕见的空白。

有时候我甚至都怀疑，就拉丁美洲的诗歌而言，500多年前的那条 因《托尔德西里亚斯条约》而诞生的“教皇子午线”是不是也存在于当 代中国的译介版图之中。这条译介上的“教皇子午线”的西班牙语美洲 一侧, 我们有着译著等身的译者和读者众多的译本, 一些尚在人世的西 语美洲大诗人, 比如Juan Gelman和José Emilio Pacheco都曾来过中国参加 诗歌活动, 而说葡萄牙语的巴西一侧, 我们则只有可怜的一点点并未引 起诗歌界关注的零散翻译, 要么出现在巴西驻华使馆自行承印的读本上 (如西班牙语译者赵德明 “客串” 翻译的《巴西诗选》和《马里奥・金 塔纳诗选》）, 要么出现在生僻的外国文学研究专业期刊之中。

大概在2004年初的时候, 我在巴西利亚客座执教的生涯已经度过了 好几个月, 凭着葡萄牙语和西班牙语的相似性, 再加上每天的自学, 我 
已经能用葡萄牙语读点东西了。不过, 因为对自己的葡语阅读能力不是 很自信, 我最开始接触到的巴西诗歌, 是Elizabeth Bishop选编的英语、 葡萄牙语双语版的Anthology of Twentieth Century Brazilian Poetry。这本书 我主要是借助词典读葡语原文部分, 如果遇到超越了我的葡语理解能力 的诗句, 我再参照英译文阅读。这本书对我产生了很大的影响, Manuel Bandeira, Carlos Drummond, Cecilia Meireles, Venicius de Moraes, Murilo Mendes, João Cabral de Melo Neto等巴西诗人的作品最初进入到我的视 野, 都是拜这本书所赐。更重要的是, 这本书开启了我翻译巴西诗歌 的念头。

我最早开始翻译的是Vinicius de Moraes的诗, 主要是Anthology of Twentieth Century Brazilian Poetry里面收选的。之所以选择Vinicius de Moraes, 是出于两方面的考虑: 一是我觉得他的诗基本都是以情感的强度见 长的抒情诗, 除了一些爆发式的夸张和率真的比喻, 他的诗并没有太多 的难度, 诗句里埋藏的路径复杂、结构精微的 “秘密通道” 并不多, 只 要把握好了他的那种膨胀、放任、充满雄性征服色彩的波希米亚 (Bohemian）抒情腔调, 翻译起来并不难; 二是因为, 在中国当代诗歌自身的 传统里，1980年代盛行于我的家乡四川的“莽汉主义” 诗歌和Vinicius的 诗在营造不羁的抒情主体、呈现抒情的爆发力这方面略有相似之处, “ 莽汉主义”诗歌在1990年代被当时注重冷峻、叙事、反讽的中国诗歌主 流所疏离, 我本人也曾一度忽视它, 但到我阅读Vinicius的那段时期, 至 少就我个人的诗歌阅读和写作而言, 我有那么一点“百无禁忌”的意思 了, 觉得主体膨胀的高强度抒情也并不一定会导致诗歌内在质地垮塌。

直接导致我产生翻译Vinicius de Moraes的冲动的, 是他在《Receita de Mulher》这首诗里的那句 “Que a mulher se socialize elegantemente em azul, como na República Popular Chinesa” 4, 在一个中国诗人的眼里, 这一句 显得非常突 $\pi$, 这里面包含了极其有趣的跨文化想像, 因为在今天的中 国人看来, 毛泽东时代身穿蓝色或者绿色军服、工装服的女性和 “美” 这个概念没有任何关系。当然, 《Receita de Mulher》整首诗写得气势磅 礴、想象力奇綗, 尽管有大男子主义塑造女性身体的性别政治错误, 但 我个人还是非常喜欢的。我刻意避免使用自己的写诗腔调, 有意把这首 诗译成了上个世纪 80 年代寓风流于粗犷的“莽汉主义”腔调。2005年我 回国后, 曾经多次在诗歌朗诵会上诵读这首诗的中译本, 听众的现场 反应都相当不错。读过我我翻译的Vinicius的中国年轻读者们还比较喜欢 引用《Soneto de Fidelidade》里面的结句 “Que não seja imortal, posto que é chama/ Mas que seja infinito enquanto dure.”，据说一些大学生在这句对“

4 Vinicius De Moraes, Soneto de Fidelidade e outros poemas. São Paulo: Ediouro, 2004, p. 53. 
忠贞” 的理解和东方传统观念大相径庭的诗句里找到了他（她）们及时 和恋人分手的崇高理由。

在我2005年离开巴西之前, 除了Vinicius之外, 我已经零零星星翻 译了一些Manuel Bandeira、Carlos Drummond, 、Mário Quintana、Paulo Leminski、Ana Cristal César的诗。但我不久之后就锁定了一个我的主要翻 译目标, 那就是巴西现代主义诗歌的集大成者João Cabral de Melo Neto。

与João Cabral的 “相遇” 对我而言是不旁是一个巨大的惊喜。我个 人的诗歌阅读趣味比较广泛, 像Garcia Lorca、Jacque Prevert那样 “简单” 的诗我很喜欢, 像Frank O'hara、Nicanor Parra那样 “即兴” 的诗我也很感 兴趣, 但最能激起我的阅读兴奋感的, 还是那些充分展示了语言内部的 复杂性和游戏性、善于通过精湛冷静的诗句呈现与现实世界相对称的高 度智性化的内心世界的诗人, 他们的诗歌既有形式上的欢愉、语义上的 曲折幽微, 更有一种使得现代诗之所以耐人寻味的集现实洞察力、语言 表现力、无边想象力为一体的综合性创造力。在我看来, João Cabral就 属于这一类诗人。

在我已经可以抛开英译本、借助字典慢吞吞地阅读葡语原文诗歌 之后, 我读的第一本葡语诗集就是João Cabral的《O Engenheiro》。我 被他冷峻、剔透、精确、执拗、充满了“原诗” (Meta-poesia) 气息却 又浸渍着鲜活的现实经验（特别是巴西东北部的独特记忆）的风格所 吸引, 他的诗句像轻盈的海绵一样, 从外到内遍布通风的孔洞, 而一 经阅读, 这些修辞的孔洞里就会吸满份量惊人的可能性的海水 (agua de possibilidade）。我在巴西利亚大学的几个学生知道我对João Cabral感兴 趣, 借给我好几本他的诗集, 印象中, 有一本选集借到我手上时已经被 翻烂了, 必须拿胶水粘起来才勉强看起来像一本书。借我这本 “破书” 的学生说, 他芧爹、他爸爸和他本人都喜欢João Cabral, 所以一家三代就 把那本书翻成那样了。我从巴西回国的行囊里, 还有一张João Cabral本人 朗诵他自己诗歌的 CD, 听他本人朗诵对于理解原作的节奏、语气、起承 转合有意想不到的帮助。

2008年前后, 我开始集中翻译了 30 多首João Cabral的诗。之所以集 中翻译他的诗, 一是因为我个人喜欢, 二是因为我觉得他的诗歌里可能 会有很多因素值得当时的中国诗歌写作界借鉴。中国当代诗歌自 1990年 代起开始检讨1980年代诗歌中过于浓重的主观色彩和过于空泛的抒情, 占据 “话语权” 的诗人大多提倡在诗歌中引入具体、可感的叙事性成 分, 来矫正诗歌中的声音与现实语境的关系。这种趋向虽然有助于建构 一种虚构与似是而非的现实多层次嵌套的复杂现代感, 但持续10多年下 来, 很多新一代的诗人们在学习1990年代诗歌的时候往往不得要领, 把 策略性的叙事变成了纯客观的叙事, 现代诗歌中包含的创造性被过多地 限制了起来。我觉得João Cabral的诗歌提供了另外一条更为智性化的“ 
反抒情” 的道路：在摈除诗歌表层情感的前提下，以冷静、严谨的姿态 在语言内部进行元语言的探索和新形式的实验, 让诗歌写作成为操纵着 具有复杂的动力装置的诗歌机器, 最终在诗歌中重新建立起 “o mundo justo,/mundo que nenhum véu encobre" 5 。

坦白地说, 比起Vinicius de Moraes来, 翻译João Cabral的工作非常 艰难。在对待诗歌翻译的态度上, 我一直相信 “诗人译诗” (英语里叫 poet as translator) 要优于任何专业的译者译诗, 我认为 Robert Frost的那个 说法（Poetry is what gets lost in translation）通过 “诗人译诗” 可以得到补 救, 作为译者的诗人可以用译入语言中相应的诗歌花饰替代原文中与译 入语无法兼容的形式机巧。但在翻译João Cabral的时候, 我发现他诗歌之 中埋藏的仅在葡萄牙语中有效的小机关实在是太密集了, 想要用当代汉 语诗歌的书写规则 “转写”一篇包含如此多的形式 “涺计” 的诗难度非 常大, 有时候我不得不放弃在汉语中重设那些形式 “栬计” 的做法, 改 为在直接译出表层语义的基础上, 通过语气、修辞的变化强化它的表达 效果, 暗示它在原文中的曲折感。比方说, 他看起来非常简单、甚至有 些Joan Miró绘画中的孩子气那首Tecendo a Manhã , 就含有很多的在汉语 中无法复现的小机关, 特别是第二诗节：

E se encorpando em tela, entre todos, se erguendo tenda, onde entrem todos, se entretendendo para todos, no toldo (a manhã) que plana livre de armação. A manhã, toldo de um tecido tão aéreo que, tecido, se eleva por si: luz balão. ${ }^{6}$

从se encorpando到se erguendo再到se entretendendo的变化, 从tela到 tenda再到toldo的递进, 最后两行里两个词性大不相同的tecido, 这些都 难以在汉语里复现。尤其是entretendendo这个João Cabral 自己发明出来 的词, 它所包含的在entre、entender、tender、tenda之间漂移的意义完 全无法找到相应的汉语表达。我本想把它翻译出当代诗人张東那种小词 与小词之间互相啮合、互相激发的效果出来, 但最后无能为力, 只能按 2000年前后汉语诗歌里最普通的“冷处理”语调译出最表层的语意来。

5 João Cabral de Melo Neto, Antologia Poética, p. 195, Rio de Janeiro: Livraria José Olympio Editora, 1978.

6 João Cabral de Melo Neto, Antologia Poética, p. 17, Rio de Janeiro: Livraria José Olympio Editora, 1978 . 
2008年, 中国诗歌圈比较权威的杂志《当代国际诗坛》做了一个 我翻译的 João Cabral 的小专题, 除了我翻译的诗, 还配了一篇我写的介 绍他的文章。这期杂志出来以后, 在诗歌界收到了不小的反响, 和 João Cabral 一样获得过 Neustadt International Prize for Literature 的中国当代最 重要的诗人之一多多激动得给我打了个电话, 说已经很多年没有读到过 这么 “有份量” 的外国诗歌了, 中国当代重要的诗歌批评家唐晓渡也在 他的文章中讨论了 João Cabral 的 Os Vazios do Homem 里面的 “空” 对 中国当代诗歌的启发 ${ }^{7}$, 而另一位重要的诗歌批评家敬文东则在他的一 篇文章里引用并讨论了 João Cabral 《A Literatura como Turismo》里面的 那句 “não nos dão seus municípios / mas outras nacionalidades” 8 。此后, 中国官方文化体制内 “级别” 最高的诗歌刊物《诗刊》也于 2011 年刊 发了一组我翻译的 João Cabral, 并邀我撰写了一篇分析 João Cabral 诗 歌特征的文章。

2011年, 我对 Carlos Drummond 死后出版的《O Amor Natural》发 生了浓厚的兴趣。之前我曾经翻译过一些 Carlos Drummond 的诗, 觉得 他的诗既能被普通读者所接受, 也能被训练有素的诗人们所肯定, 但因 为精力有限, 没有展开对他的集中翻译。很偶然的机会, 我在网上读到 了电子版《O Amor Natural》的全部诗歌, 我对一个老耆老人能够以如 此富有想象力的语言来处理最直接的性爱话题感到很意外。中国诗歌缺 乏色情诗的传统, 这大概和东亚文化对性爱遮遮掩掩有一定的关系。近 些年来, 也有一些流派和个人有过 “泛色情诗写作” 的经典案例, 但那 些 “泛色情诗” 都是假借性爱主题与身体语言来关注其他问题。比如10 多年前有个青年诗人的流派叫“下半身写作”, 他们写了很多与性有关 的东西, 但他们的焦点并不在性爱本身, 而在通过书写性爱实现对文学 秩序的反叛。也有一些顶尖的诗人, 成功地把敏感的历史和现实政治问 题放置到色情诗的框架中来处理。但几乎没有任何中国当代诗人能够直 接面对性爱, 把性能量本身不仅仅当作激情, 更当作一种创造性的诗歌 话语资源来加以利用。我翻译了《O Amor Natural》里面一半的诗, 张 贴到了“文艺青年”最集中的一个网络社区里, 结果收到了极好的反 馈, 很多读者给我写信, 说读了 Carlos Drummond 的这些诗, 既改变了 他们 “性爱不可言说” 的陈见, 又改变了他们对诗歌的认识一一诗居然 可以这么有趣! 但我对《O Amor Natural》的传播也仅仅到网络为止了, 我曾试图联系一家专门出版小众文学读物的出版社将这本诗集的中译本 正式出版出来, 但尽管编辑本人很喜欢这些诗, 她也不得不无奈地告诉

\footnotetext{
7 Tang Xiaodu, "Preface", Comtemporary International Poetry, Vol. $2^{\text {nd }}$, Beijing: China Writers Publishing House, 2008.

8 João Cabral de Melo Neto, Museo di Tutto, p. 56, Milano: Libri Scheiwiller, 1990.
} 
我, 中国目前现有的出版规定是不允许《O Amor Natural》正式出版的。 不过, 倒是有另一家出版社主动联系我, 他们从 Carlos Drummond 这批 色情诗里看到了他精湛而又没有远离普通读者的诗艺, 因此邀请我翻译 他的《O Amor Natural》之外的诗歌用以正式出版。

有一件很有意思的事情, 就是中国读者对以 Horaldo de Campos和 Augusto de Campos 为代表的 Concretistas 的态度。我曾经在我的 “现代主 义以来的世界诗歌” 课堂上讲过巴西的 Concretismo, 也曾在一些杂志上 撰文介绍过 Concretismo 和 Neo-concretismo, 但我发现中国诗人们（无 论是学校里的青年诗人还是学校外的成名诗人们) 对 Concretismo 几乎毫 无兴趣。这倒不是一个孤立的现象, 中国当代诗歌尽管极富创新精神, 但却很少涉足具体诗（poesia concreta）、视觉诗、声音诗等实验性的领 域。我认为造成这一现象的原因主要有两个: 一是中文本身就是象形文 字, 具有强烈的视觉指向, 所以中国诗人们并不像西方同行们那样热衷 于通过改变文字的物理属性来获得视觉效果; 二是中国从古至今对“ “ 诗” 这一门类的界定都很严格, 尽管在当代中国, 诗曾经一度以富于自 我革新精神而自居, 但还是始终存在这一条很微妙的边界一一似乎大家 都有一个不成文的共识, 像具体诗、视觉诗、声音诗、多媒体诗这类的 作品, 已经早就跨过了诗的边界, 进入当代艺术 (Arte Contemporanea) 的领域了, 而在当代中国, 当代诗和当代艺术之间只有一些零星的跨界 （cross over）尝试, 大多数时候基本井水不犯河水。所以我所介绍的巴 西 Concretismo、Neo-concretismo 和 Poesia Visual 只有两类读者有一点兴 趣: 一是大学里学习计算机的geek们, 二是个别当代艺术家。

最后我想说的是, 我的葡萄牙语水平其实非常有限, 它限制了我 更深入、更大量地翻译巴西诗歌。我虽然不相信 Poetry is what gets lost in translation, 但我也不是特别认同与原文差别很大的 tra-creação, 我始终 坚信即使是“诗人译诗”, 最好也还是要从原文译过来, 不要通过英语 等其他语言转译 (Ezra Pound 不懂中文却“翻译” 唐诗的案例, 在我看 来只能算是他的创作, 和翻译没有太大的关系），如果有一天我的葡语 水平能得到迅速的提升, 我肯定会翻译更多的巴西诗歌。不过我相信, 即使有那么一天, 我也不是一个值得信赖的专业译者, 因为从前面的叙 述中你可以感觉到, 我做翻译大多数时候是为自己的诗歌写作服务的, 我翻译诗歌的活跃期, 一般都是我自己诗歌写作的瓶颈期, 在写不出诗 又不愿离开诗的时候, 做点诗歌翻译是最好的选择, 正如美国诗人、翻 译家Kenneth Rexroth在《The Poet as Translator》中所说 :

Translation, however, can provide us with poetic exercise on the highest level. It is the best way to keep your tools sharp until the great job, the great moment, comes along. More important, it is an exercise of sympathy on the highest level. The writer who can project 
himself into the exultation of another learns more than the craft of words. He learns the stuff of poetry. It is not just his prosody he keeps alert, it is his heart. The imagination must evoke, not just a vanished detail of experience, but the fullness of another human being. ${ }^{9}$

（翻译能给我们提供一种高层次的诗艺操练。翻译是在伟大的劳 作、伟大的时刻到来之前, 让我们的诗歌工具永葆锐利的最佳方式。更 重要的是, 它是一种高层次的同情心操练。一个能够将自己投射到别人 的狂喜之中去的作家, 会在词语的手艺之外学到更多的东西。他学到了 诗歌的内质。它不仅仅是他一直高度重视的韵律学, 而是他的心智。在 翻译中，想象力一定会唤醒的，不仅只是一段消逝了的经验的细节，而 是另一个人类个体的丰满度。)

9 Kenneth Rexroth, "The Poet as Translator", World outside the window: the selected essays of Kenneth Rexroth, p. 171, New York: New directions Publishing, 1987. 